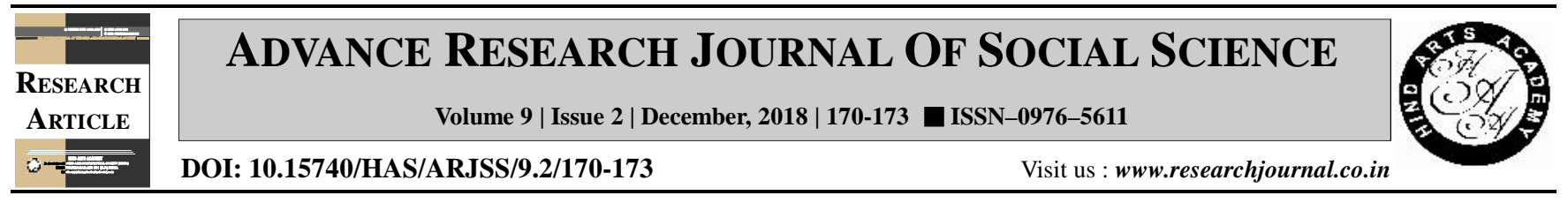

\title{
Well being of middle aged couples : Herald for social upliftment
}

Sangeeta Bhatt* and Gaytri Tiwari

Department of Human Development and Family Studies, College of Home Science, Maharana Pratap University of Agriculture and Technology, Udaipur (Rajasthan) India

(Email : bhattsangeeta94@gmail.com; tiwarigaytri@gmail.com)

\section{ARTICLE INFO :}

$\begin{array}{lll}\text { Received } & : & 21.05 .2018 \\ \text { Revised } & : & 07.11 .2018 \\ \text { Accepted } & : & 10.11 .2018\end{array}$

\section{KEY WORDS :}

Middle aged couples, Well being

\section{HOW TO CITE THIS ARTICLE :}

Bhatt, Sangeeta and Tiwari , Gaytri (2018). Well being of middle aged couples : Herald for social upliftment. Adv. Res. J. Soc. Sci., 9 (2):170-173, DOI: 10.15740/HAS/ARJSS/9.2/170-173. Copyright@2018 : Hind Agri Horticultural Society

*Author for correspondence

\begin{abstract}
Middle adulthood is a time period identified with the onset of changes and crisis. It is that stage of life span development where an individual is expected to fulfill multiple interpersonal and intrapersonal roles. With the advent of many challenges and expectations, it is imperative for the individuals to look for a mid way path so as not to sacrifice the harmony of life and well being. Good level of well being during this period of life is important as middle age is the preparatory time for old age and reflection time for early years. Therefore, the present study was conducted with an objective to assess the level of well being among middle aged couples. The total sample consisted of 100 couples belonging to the age range of $50-60$ years. A self prepared preliminary and background information performa was used to collect the information regarding the personal and background aspect of the subjects. Well Being Scale by Singh and Gupta (2001) was administered on the subjects to assess the level of well being. The data was collected through administering the suitable tools on selected subjects by approaching at home, work place. The data obtained were analyzed in the light of objectives by calculating frequency, percentage and mean scores. Major findings of the study indicated that majority of the couples had average level of well being. It was also revealed that the couples had highest level of spiritual well being and lowest level of physical well being.
\end{abstract}

